\title{
The behaviour of as-applied and artificially weathered silica-epoxy consolidants on a typical Mediterranean porous limestone: a comparison with TEOS
}

\author{
Sophie M. Briffa and Daniel A. Vella*
}

\begin{abstract}
A water based epoxy-silica consolidant and variants of the same consolidant containing silica nanoparticles (NP) were applied to Globigerina Limestone (GL) blocks by brushing and full immersion techniques. The consolidants were applied for their improved strength, toughness and adhesion to the stone surface. As-consolidated dried stone blocks were characterised (colour, total porosity, pore size distribution and microstructure) and their physical and mechanical properties assessed by a water uptake by capillary test, drilling resistance and resistance to salt crystallisation test. In another set of experiments, the consolidated limestone blocks were subject to 28 wet-dry cycles (8-h wet, 16-h dry) in a weathering chamber. The physical and mechanical properties of the weathered consolidated limestone blocks were then re-assessed. Parallel tests were also performed on tetraethyl orthosilicate (TEOS)-consolidated and untreated GL blocks. The water absorption coefficients of limestone blocks consolidated by brush-applied epoxysilica dropped marginally. No significant changes to the water absorption coefficients were recorded after weathering. The drilling resistance curves showed a clear improvement of the mechanical properties of epoxy-silica treated $G L$, but the effects of the consolidants were reversed with weathering. The epoxy-silica consolidants reduced the resistance of $G \mathrm{~L}$ to salt crystallisation. This resistance was partly restored after weathering, corroborating the drilling resistance results, and supporting the consolidation reversal hypothesis. Test results for the epoxy-silica consolidants applied by immersion showed similar trends, albeit complicated by pore blocking. The formation of an undesirable surface crust with epoxy-silica consolidants remains a pertinent issue with such hybrid materials. The behaviour of TEOS-consolidated GL was very different to the epoxy-silica consolidants and this can be traced to the hydrophobic nature of TEOS that persisted months after application.
\end{abstract}

Keywords: Globigerina Limestone, Silica-epoxy consolidant, Silica nanoparticles, Drilling resistance, TEOS, Accelerated weathering

\section{Introduction}

The weathering and deterioration of outdoor exposed stone monuments and buildings is an inevitable natural process. Stone decay is limited to the immediate stone surface and progresses inwards at a rate determined by the properties of the stone, and the severity of the surrounding environment. Atmospheric pollution, the

${ }^{*}$ Correspondence: daniel.vella@um.edu.mt

Faculty of Engineering, Department of Metallurgy and Materials

Engineering, University of Malta, Msida MDS 2080, Malta presence of soluble salts and bio-mediated decay are identified as the main contributors to the deterioration of outdoor stone work [1]. The need to preserve stone and slow down the deterioration process is thus pertinent. In conservation-restoration practice, consolidants are employed to mechanically support fragile decaying surface stone. A stone consolidant acts by penetrating the stone pore network attaching itself to surfaces, and linking weakened surface material to the healthier surrounding stone $[1,2]$. Consolidants that penetrate deeply, improve resistance to 
salt weathering and preserve the aesthetical and physical properties of the stone are favoured [1,3].

Consolidants based on alkoxysilane precursors [2] are commonly employed in the preservation of stonework. An advantage of these materials over organic polymers is that they are applied as low molecular weight monomers or oligomers that polymerize to form consolidants inside the stone [4]. The implicitly low viscosities of the starting materials greatly improve penetration depths. One of the simplest alkoxysilanes employed in commercial formulations is tetraethylorthosilicate (TEOS). TEOS is known to be very effective over sandstones but less so on limestone [4]. In the former, the consolidant forms strong covalent links with the stone surface silanol groups $(\equiv \mathrm{Si}-\mathrm{OH})[4]$. These bonds do not occur over limestone surfaces [4].

Wheeler suggested the use of organoalkoxysilane hybrid precursors $\mathrm{R}-\mathrm{Si}(\mathrm{OR})_{3}$ where the $\mathrm{R}-\mathrm{Si}$ bond is un-hydrolysable and the functional $\mathrm{R}$-group serves to improve adhesion of the consolidant to the limestone surface [4]. These materials, referred to as adhesion promoters, can be applied directly to the stone as a pre-treatment to consolidation. This route was explored by $\mathrm{Xu}$ and co-workers [5] who evaluated two organoalkoxysilanes with amino and phosphate functionalities. Alternatively, the hybrid precursor can be directly incorporated in the consolidant formulation [4]. Cardiano and colleagues [6] have synthesised a number of epoxy-silica consolidants which they applied to calcite and quartz rich stones for consolidation and protection against water penetration. Kim and co-workers [7] incorporated various sizes of silica NP and the hybrid precursor 3-glycidoxypropyl trimethoxysilane (GPTMS) to TEOS producing a number of new consolidants, which they compared to a commercial consolidant containing TEOS. The prepared consolidants were crack-free and when applied to Korean Granite, reduced water infiltration notwithstanding the apparent increase in hydrophilicity of the consolidant with GPTMS additions [7]. De Ferri and colleagues [8] prepared water-repellent protective treatments for marble, sandstone and granite stone types based on mixtures of GPTMS and Dynasylan $40^{\circledR}$ loaded with surface modified silica NP. Xu and co-workers [9] prepared epoxy-silica hybrid consolidants modified with hydroxyl-terminated poly(dimethylsiloxane) (PDMS-OH) for limestone treatment. PDMS-OH was incorporated to enhance the flexibility of the deposited consolidant films, decreasing volume shrinkage and preventing cracking [9]. The presence of the methyl $\left(-\mathrm{CH}_{3}\right)$ groups also improved the hydrophobicity of the consolidant [9].

\section{Research aims}

In this research, a water-based epoxy-silica consolidant and variants loaded with 10-20 nm silica NP were applied to quarried GL blocks by brush and full immersion. Consolidants prepared from binary mixtures of GPTMS and TEOS (henceforth epoxy-silica), with or without nanoparticles, were applied for their improved strength, toughness and adhesion to the stone surface.

The aesthetical, physical and mechanical properties of the dried epoxy-silica consolidated limestone were evaluated before and after an accelerated weathering protocol employed to simulate limestone exposed outdoors. The consolidating properties of the prepared epoxy-silica consolidants were compared to those of TEOS. To the authors' best of knowledge, accelerated weathering of epoxy-silica consolidated porous limestones has never been attempted.

\section{Methods}

The flow chart in Fig. 1 presents an overview of the Method.

\section{Limestone source}

Maltese Globigerina Limestone blocks, sub-type franka, measuring $(50 \times 50 \times 50) \mathrm{mm}^{3}$ were dry-cut from a quarry in Mqabba, situated to the South East of Malta $\left(35^{\circ} 50^{\prime} 38.634^{\prime \prime}\right.$ latitude and $14^{\circ} 27^{\prime} 13.4562^{\prime \prime}$ longitude). Franka-type Globigerina Limestone is a calcitic stone ( $~ 93 \%$ calcite) with total porosity in the range 32 to $41 \%$ [10]. GL is described as a soft limestone that easily wets and can soak up a large volume of water during rain periods [11]. It is formed from numerous tightly packed and cemented microfossils. The stone type is widely found in the Mediterranean basin including Turkey, Israel, Tunisia, Spain and Italy [12].

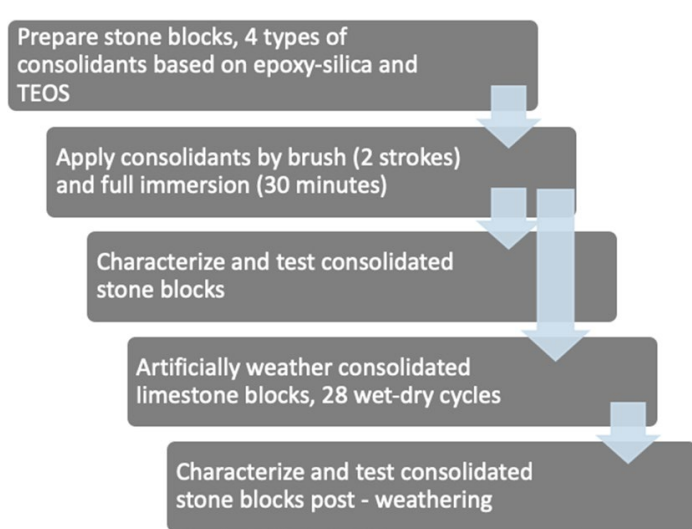

Fig. 1 Flow chart outlining the method 


\section{Materials}

The following consolidant precursor materials were used as received without further purification: tetraethylorthosilicate (Aldrich), 3-(glycidoxypropyl)trimethoxysilane (GPTMS) (Aldrich). Dibutyltin dilaureate (DBTL) (Aldrich, Fluka Analytical) and acetic acid (Aldrich) were used to catalyse the condensation-polymerization of TEOS and TEOS-GPTMS consolidants respectively. Diethylenetriamine (DETA) (Aldrich) was used as the organic cross-linker.

\section{Preparation of consolidants}

Four different consolidants were prepared and tested in this study:

\section{TEOS}

TEOS consolidant was prepared by mixing tetraethylorthosilicate, double distilled water $\sim 0.05 \mu \mathrm{S} /$ $\mathrm{cm}$, and absolute ethanol (Chromosolv, Aldrich) in a mole ratio of 1:2:5 in accordance with an earlier study [13]. The concentration of silica in the final sol was $11.5 \%(\mathrm{w} / \mathrm{v})$. The catalyst DBTL $1 \%(\mathrm{v} / \mathrm{v})$ was added to promote the hydrolyses-polycondensation reactions. TEOS consolidant was applied to the limestone blocks immediately after preparation.

2. Epoxy-silica

The preparation of the epoxy-silica consolidant was adapted from earlier works on nanostructured materials $[14,15]$ : a 1:3 mol ratio mixture of TEOS to GPTMS was added drop-wise to $0.05 \mathrm{M}$ aqueous acetic acid with continuous mixing. The mole ratio total silica (TEOS + GPTMS) to acidified water was $1: 14$. The resulting mixture was allowed to stir for $72 \mathrm{~h}$ at room temperature to achieve a final sol with a silica concentration of $24 \%(\mathrm{w} / \mathrm{v})$. Prior to application onto the limestone, the sol was diluted with 4 volume-parts water to achieve $\sim 5 \%(\mathrm{w} / \mathrm{v}) \mathrm{SiO}_{2}$ and $1 \%(\mathrm{v} / \mathrm{v})$ DETA was added to promote organic crosslinking to form the final consolidant.

3. Epoxy-silica with nanoparticles (NP)

The nanoparticle-loaded consolidants were prepared by slowly adding silica NP (Sigma-Aldrich, 10-20 nm) to mechanically stirred epoxy-silica so that the final concentration of NP in the hybrid reached $10 \%(\mathrm{w} / \mathrm{v})$. The nanoparticle-loaded consolidant was diluted and cross-linked in the same way as the epoxy-silica.

4. Epoxy-silica with modified NPs

This consolidant was prepared as in point (3) but nanoparticles were surface modified with epoxygroups. The surface modification of the NP with GPTMS was carried out as follows: GPTMS was added slowly in a dropwise manner to a mixture of acidified water (0.05 M acetic acid) containing the silica NP. The mole ratio GPTMS: acidified water: silica NP was set at 1:18.75:20. The GPTMS was allowed to react by mixing for $24 \mathrm{~h}$.

\section{Mode of application}

Consolidants were applied by two consecutive brush applications (all sides) or by full immersion where the GL blocks were submersed for $30 \mathrm{~min}$ in the consolidant to ensure even application. Consolidated stone blocks were allowed to air-dry under ambient laboratory conditions for 5 week to ensure complete drying. Untreated GL blocks were used as controls.

\section{Artificial weathering}

Consolidated and untreated limestone test blocks were subject to 28 wet-dry cycles in an Aster (CNS 500) water fog chamber. In the wet cycle GL blocks were exposed to distilled water mist for $8 \mathrm{~h}$ at $35{ }^{\circ} \mathrm{C}$. The dry cycle consisted of $16 \mathrm{~h}$ drying at room temperature $\left(22-25{ }^{\circ} \mathrm{C}\right)$, and humidity $(\sim 50-60 \% \mathrm{RH})$. The artificial weathering regime was partly inspired by the daily/and seasonal outdoor humidity cycles experienced in Malta. A wet-dry cyclic regime as opposed to continuous wetting is therefore more representative of a real outdoor environment. During the wet cycle, sparingly soluble materials may dissolve in water films and reprecipitate during the dry period leading to more pronounced materials alteration. The higher set temperature accelerates reaction rates.

The authors appreciate however that artificial accelerated weathering cannot be used to predict real time degradation in the field.

\section{Characterization and testing}

L*a*b* colour parameters were measured using a Minolta CM-50 8i spectrophotometer according to Palazzi [16]. Changes to the stone colour with application of consolidants $\left(\Delta \mathrm{E}_{\mathrm{a}}\right)$ and after weathering $\left(\Delta \mathrm{E}_{\mathrm{w}}\right)$ were assessed according to the equation $\Delta \mathrm{E}=\left[\left(\Delta \mathrm{L}^{*}\right)^{2}+\left(\Delta \mathrm{a}^{*}\right)^{2}+\left(\Delta \mathrm{b}^{*}\right)^{2}\right]^{1 / 2}$ where $\mathrm{L}^{*}$ represents the degree of lightness $\left(L^{*}=0-100,0\right.$ signifies black and 100 is white), $a^{*}$ represents redness $\left(a^{*}>0\right)$ to green $\left(a^{*}<0\right)$, and $b^{*}$ yellowness $\left(b^{*}>0\right)$ to blue $\left(b^{*}<0\right)[16]$. Colour measurements were carried out in triplicated over different treated surfaces on the same stone block. For an ideal consolidant, the surface of the treated stone is left looking the same after treatment.

The interaction between the consolidant and limestone was probed by a Merlin-Zeiss Field Emission Scanning Electron Microscope. Electron micrographs of fractured untreated and treated limestone samples were generated 
under an electron beam accelerating voltage of $3 \mathrm{kV}$ and a probe current of $125 \mathrm{pA}$. The working distance was set between 4 and $8 \mathrm{~mm}$. Untreated and treated limestone surfaces were sputter coated with graphite to improve electrical conductivity of the surface prior to their observation.

Porosity measurements were carried out on immersion consolidated $10 \mathrm{~mm} \times 10 \mathrm{~mm} \times 10 \mathrm{~mm}$ GL samples extracted from the treated and untreated limestone treated block surfaces using a Quantochrome Pore Master Mercury Porosimeter. The respective densities of the extracted stone samples were determined using a Ultrapyc 1200 e automatic density analyser. The density of the stone samples was required to measure porosity.

The water flow characteristics of consolidated GL test blocks and resistance to salt crystallization were assessed respectively as per EN1925:1999 and EN 12370:1999. After consolidation treatment, the water flow characteristics of a porous limestone should as much as possible be left unaltered. Consolidants that block/inhibit free movement of water through a pore network can potentially damage the stone fabric in the long run, especially if the water is carrying soluble salts. The resistance to salt crystallization test determines the resistance of the stone pore network to salt crystallization pressure. Limiting the flow of soluble salts inside a porous limestone could lead to the undesirable effects of salt inflorescence.

Improvement to the mechanical properties of the stone after consolidation were assessed using a lab-built drilling resistance measuring apparatus. The latter was equipped with a $10 \mathrm{~mm}$ flat-edged masonry drill bit and calibrated $5 \mathrm{~kg}$ load cell for measuring the drilling force $(\mathrm{N})$. The drilling resistance apparatus used in this work was built around a Chester Machine Tools Micro-mill modified to record the drilling resistance. The drilling speed and feed rate were set to $1000 \mathrm{rpm}$ and $15 \mathrm{~mm} / \mathrm{min}$ in line with the work of others [17]. The drilling depth was set to $10 \mathrm{~mm}$. The load cell was calibrated using standard weights before each drilling resistance measurement campaign.

All physical and mechanical tests listed above were carried out in triplicate.

\section{Results \\ Colour}

$\mathrm{L}^{*} \mathrm{a} \mathrm{a}^{*}$ values for brush and immersed consolidants before and after artificial weathering are presented in Table 1. Brush-applied epoxy-silica consolidants led to a marginal drop in $L^{*}$ and an increase in the value of $b^{*}$ suggesting some darkening, and yellowing of the stone blocks. TEOS applied by brush did not alter the appearance of the stone. Epoxy-silica consolidants applied by immersion led to considerable darkening (drop in $\mathrm{L}^{*}$ ), reddening and yellowing of GL. TEOS applied by immersion led to a slight darkening, but stone colour was preserved.

Weathering resulted in considerable darkening reddening and yellowing of untreated and brush-consolidated GL including TEOS. GL contains iron rich minerals $(\sim 0.2-1.6 \mathrm{wt} \%)$ that on contact with water can transform to more stable forms such as haematite and goethite, respectively red and yellow coloured [18]. The formation of these minerals could explain the observed colour changes. We have tried unsuccessfully to carry our $\mathrm{x}$-ray diffraction on these samples to determine the iron mineral phases. Unfortunately the calcite phase dominates the diffractogram.

It is generally agreed that stone colour variations induced by consolidant uptake should ideally fall in the range $\Delta \mathrm{E} \leq 5$ [19-21]. A value of $\Delta \mathrm{E}=2$ is considered as a perceivable difference in colour when comparing two surfaces side by side, whereas a value of $\Delta \mathrm{E}>5$ is a colour difference perceived even without confronting the surfaces. In this work, the application method profoundly

Table 1 L*a*b* colour data for as-consolidated and consolidated-weathered GL

\begin{tabular}{|c|c|c|c|c|c|c|c|}
\hline \multirow[t]{2}{*}{ Application method } & \multirow[t]{2}{*}{ Consolidant system } & \multicolumn{3}{|c|}{ As applied consolidant } & \multicolumn{3}{|l|}{ Weathered } \\
\hline & & $\mathrm{L}^{*}$ & $a^{*}$ & $\mathbf{b}^{*}$ & $\mathrm{~L}^{*}$ & $a^{*}$ & $\mathbf{b}^{*}$ \\
\hline & Untreated limestone & $83.24 \pm 1.39$ & $2.25 \pm 0.36$ & $16.02 \pm 1.43$ & $71.08 \pm 0.88$ & $5.23 \pm 0.48$ & $24.72 \pm 1.11$ \\
\hline \multirow[t]{4}{*}{ Brush } & TEOS & $82.29 \pm 0.67$ & $2.65 \pm 0.21$ & $18.09 \pm 0.89$ & $72.43 \pm 0.89$ & $5.16 \pm 0.52$ & $24.91 \pm 0.98$ \\
\hline & Epoxy-silica & $76.60 \pm 1.97$ & $4.65 \pm 0.75$ & $25.58 \pm 2.23$ & $69.20 \pm 0.83$ & $5.74 \pm 0.25$ & $26.43 \pm 0.81$ \\
\hline & Epoxy-silica + NP & $80.54 \pm 1.18$ & $3.29 \pm 0.29$ & $19.50 \pm 1.48$ & $70.00 \pm 1.00$ & $5.54 \pm 0.43$ & $26.13 \pm 1.05$ \\
\hline & Epoxy-silica + modified NP & $79.69 \pm 1.14$ & $3.48 \pm 0.42$ & $21.32 \pm 1.48$ & $69.42 \pm 0.93$ & $5.62 \pm 0.37$ & $26.03 \pm 0.55$ \\
\hline \multirow[t]{4}{*}{ Full immersion } & TEOS & $80.81 \pm 2.33$ & $3.38 \pm 0.55$ & $18.37 \pm 2.70$ & $81.26 \pm 2.63$ & $2.80 \pm 0.74$ & $16.57 \pm 3.14$ \\
\hline & Epoxy-silica & $67.08 \pm 1.34$ & $8.02 \pm 0.67$ & $31.54 \pm 0.87$ & $72.49 \pm 1.97$ & $3.65 \pm 0.57$ & $20.82 \pm 8.02$ \\
\hline & Epoxy-silica +NP & $69.08 \pm 1.08$ & $7.67 \pm 0.53$ & $31.72 \pm 0.88$ & $70.03 \pm 1.98$ & $4.83 \pm 0.86$ & $21.71 \pm 2.27$ \\
\hline & Epoxy-silica + modified NP & $75.89 \pm 1.88$ & $4.89 \pm 0.86$ & $27.47 \pm 3.49$ & $69.06 \pm 1.35$ & $6.07 \pm 0.24$ & $27.02 \pm 0.78$ \\
\hline
\end{tabular}



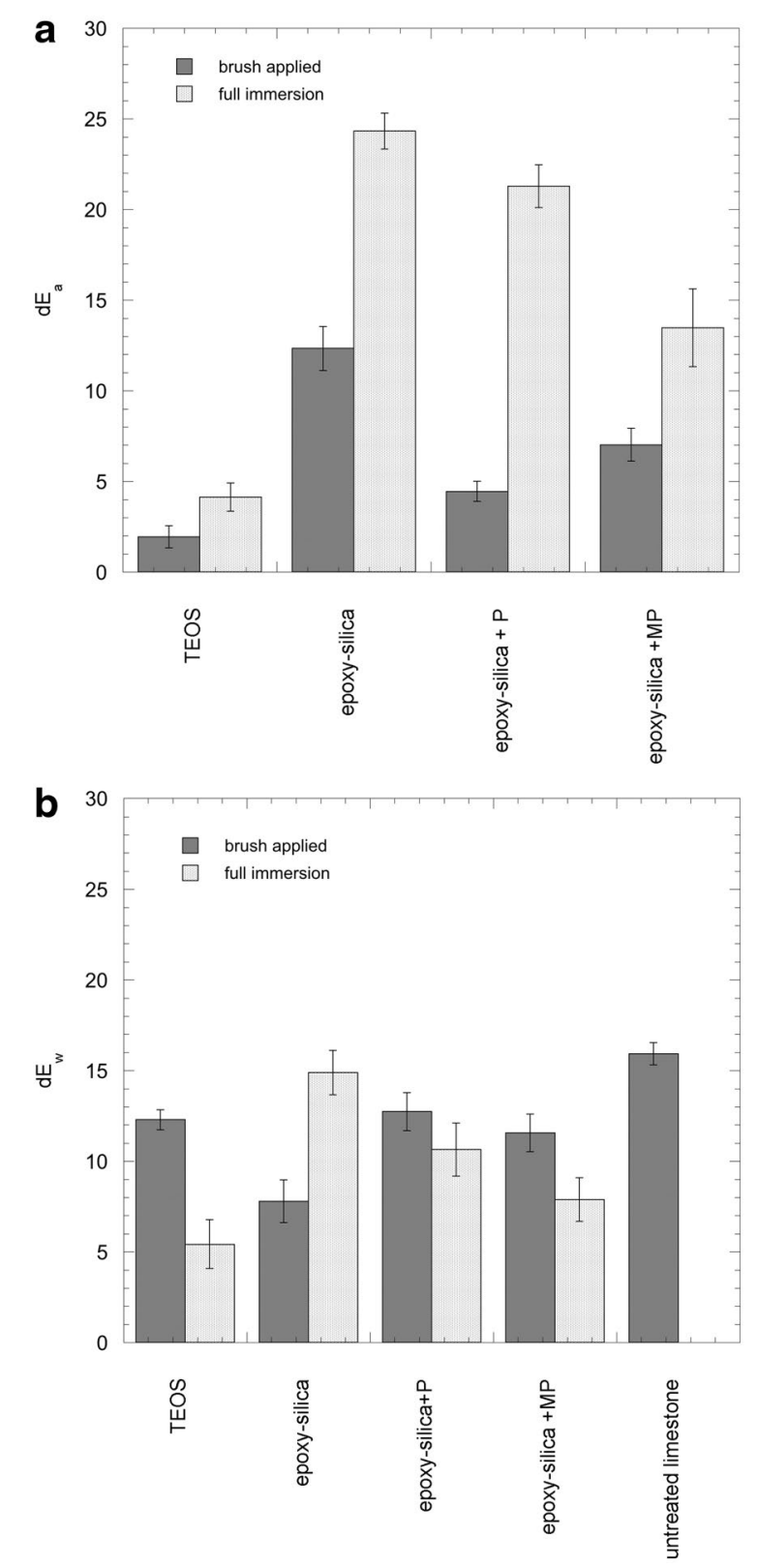

Fig. 2 a $\Delta E_{a}$ for $G L$ treated with different consolidants, $\mathbf{b} \Delta E_{w}$ for treated and untreated GL subject to weathering. $P$ and $M P$ refer to NP and modified NP

influenced the $\Delta \mathrm{E}$ values. Stone blocks consolidated by brush resulted in a noticable change to the colour of the stone $\left(\Delta \mathrm{E}_{\mathrm{a} \text {,brush }} \sim 5-12\right)$. Addition of silica NP aided to reduce this effect, see Fig. 2a, yet the colour change was still above limit, $\Delta \mathrm{E} \geq 5$. Fully immersing GL in epoxysilica gave rise to the more intense and unacceptable chromatic changes, $\Delta \mathrm{E}_{\mathrm{a} \text { immersion }} \sim 15-25$. Irrespective of the application method, TEOS resulted in the most acceptable chromatic change $\Delta \mathrm{E}_{\mathrm{a}} \leq 5$ This fact was also reported by others using commercial TEOS on calcitic stone [4].

Figure $2 b$ charts surface colour changes for untreated and consolidated limestone blocks after weathering. The surface colour of all consolidated GL blocks was altered, but so has untreated limestone, $\Delta \mathrm{E}_{\mathrm{w}} \sim 15.9 \pm 0.6$. In fact, weathered unconsolidated limestone resulted in the highest recorded $\Delta \mathrm{E}_{\mathrm{w}}$, higher than any of the consolidated stone blocks.

\section{Stone-consolidant microstructure}

Electron micrographs of non-weathered untreated and immersion-consolidated limestone specimens are presented in Fig. 3a-e. The consolidant films appear homogenously deposited over the internal pore walls. While TEOS, epoxy-silica and epoxy-silica + modified nanoparticle films are smooth, the hybrid loaded with NP appears particulate in nature, Fig. 3d. Brinker cited in Miliani argues that in silicate sols, addition of $10-20 \mathrm{~nm}$ silica NP serve as nucleation sites for precipitation of the sol $[20,22]$. A similar effect, namely that the added silica NP seed the sol resulting in larger particulate aggregates, was observed in this work for the nanoparticle loaded consolidants.

The epoxy-silica films do not feature macro-cracks typically reported for TEOS [4]. Nonetheless microcracks were observed at sites where calcite microcrystal beds grow perpendicular to the pore surfaces, see for example Fig. 3d. These micro-cracks occurred predominately at the base of micro-crystallites, at sharp corners where the consolidant evidently accumulates. Overall, the incorporation of flexible organic groups led to more plastic and tougher consolidant matrices that are less prone to crack. Cracks are further avoided through the inclusion of the NP. TEOS films deposited in this work were crack-free, suggesting perhaps that longer ageing periods are required before shrinkage cracks set in.

\section{Porosity and pore size distribution}

The pore size distribution curves for as-consolidated immersed and consolidated-weathered limestone blocks are presented in Fig. 4a, b. The corresponding percentage open porosities are given in Table 2 . The $\%$ open porosity of untreated GL was $39.9 \%(\mathrm{v} / \mathrm{v})$. The pore size distribution consists of a main curve with an average pore size of $\sim 2-3 \mu \mathrm{m}$ (over $65 \%(\mathrm{v} / \mathrm{v})$ of the pores $>1 \mu \mathrm{m}$ ) and a shoulder with a centre point at $\sim 0.4 \mu \mathrm{m}$, Fig. $4 \mathrm{a}$. The \% open porosity and pore size distribution agree with results achieved by others for franka GL [10, 11]. In general, consolidation treatments lowered the total open porosity by about $3-5 \%(\mathrm{v} / \mathrm{v})$ with the largest drop 


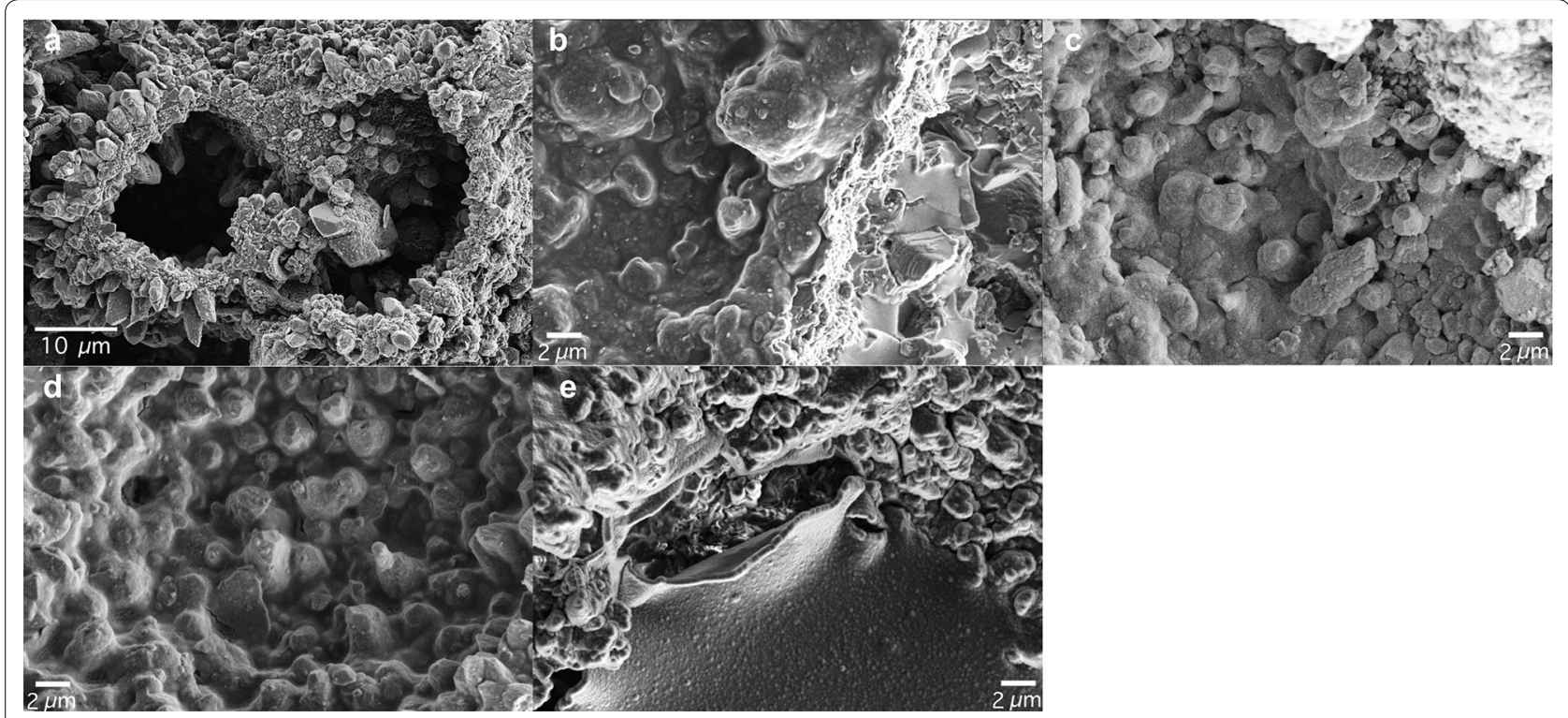

Fig. 3 Electron micrographs of a untreated GL, b TEOS-treated, c epoxy-silica, d epoxy-silica with NP, e epoxy-silica with surface-modified NP

recorded for epoxy-silica with silica NP, Table $2 \mathrm{~b}$. As observed in Fig. 4a, the various consolidation treatments do not alter significantly the larger pores, but do alter the pore size distribution of the smaller pores. This is in general agreement with the electron micrographs which show consolidant films lining the larger pores rather than filling or blocking the pores.

Artificial weathering increased the percentage open pores, with most consolidant-limestone systems approaching the value of untreated limestone $\sim 39.9 \%$ $(\mathrm{v} / \mathrm{v})$, Table 2 . Figure $4 \mathrm{~b}$ compares the pore size distribution for untreated-weathered and consolidated-weathered limestone; the general pore size distribution for the different consolidants after weathering remained pretty much the same.

\section{Limestone water transport properties}

Representative curves of water uptake by capillarity for brush-consolidated GL blocks (as-applied, and after weathering) are given in Fig. 5a, b while the corresponding average water absorption coefficients are provided in Table 2 and Fig. 6a. The \% water absorbed into the stone after $24 \mathrm{~h}$ is also given in Table 2. Epoxysilica consolidants have reduced, albeit marginally, the absorption coefficient of GL. This is unlike TEOS where the value dropped substantially $\sim 3.54 \pm 1.25 \mathrm{~g} / \mathrm{m}^{2} / \mathrm{s}^{1 / 2}$. Scherer and Wheeler [23] argue that this drop results from the presence of hydrophobic ethoxy-groups that remain bound to the silicate polymer months after drying. Weathering has the effect of reducing the water absorption coefficient of untreated limestone $\sim 7.72 \pm 0.44 \mathrm{~g} / \mathrm{m}^{2} / \mathrm{s}^{1 / 2}$ but does not alter the water flow characteristics of the epoxy-silica hybrids, nor for that matter the absorption coefficient of TEOS consolidated limestone, which remains practically unaltered at $2.73 \pm 0.39 \mathrm{~g} / \mathrm{m}^{2} / \mathrm{s}^{1 / 2}$.

Representative water uptake by capillarity curves for immersion-consolidated GL are given in Fig. 5c, d while the corresponding average absorption coefficients are provided in Table 2 and Fig. 6c. The water absorption coefficients of epoxy-silica and nanoparticle-loaded hybrid applied by full immersion are comparable to TEOS $\sim 0.52 \pm 0.37 \mathrm{~g} / \mathrm{m}^{2} / \mathrm{s}^{1 / 2}$. Epoxy-silica loaded with modified NP presented a higher average absorption coefficient $\sim 6.10 \pm 0.89 \mathrm{~g} / \mathrm{m}^{2} / \mathrm{s}^{1 / 2}$. Weathering resulted in a significant improvement of the water absorption coefficients for epoxy-silica consolidants. Values for epoxy-silica, hybrid with NP, and hybrid with modified NP were respectively $2.37 \pm 0.54 \mathrm{~g} / \mathrm{m}^{2} / \mathrm{s}^{1 / 2}$, $3.49 \pm 0.71 \mathrm{~g} / \mathrm{m}^{2} / \mathrm{s}^{1 / 2}$ and $7.87 \pm 2.00 \mathrm{~g} / \mathrm{m}^{2} / \mathrm{s}^{1 / 2}$, with the latter closer to that of untreated weathered limestone. The results suggest that the epoxy-silica consolidants interact better with water. Indeed, the water contact angle of an epoxy-silica thin film prepared at our labs in similar way to the consolidants used in this work, but cured at $150{ }^{\circ} \mathrm{C}$ for $1 \mathrm{~h}$ was measured to be $65 \pm 2{ }^{\circ} \mathrm{C}$ indicating reasonably good interaction with water [24]. TEOS treated limestone on the other hand did not alter with weathering, the absorption coefficient remaining a mere $0.20 \pm 0.035 \mathrm{~g} / \mathrm{m}^{2} / \mathrm{s}^{1 / 2}$. 

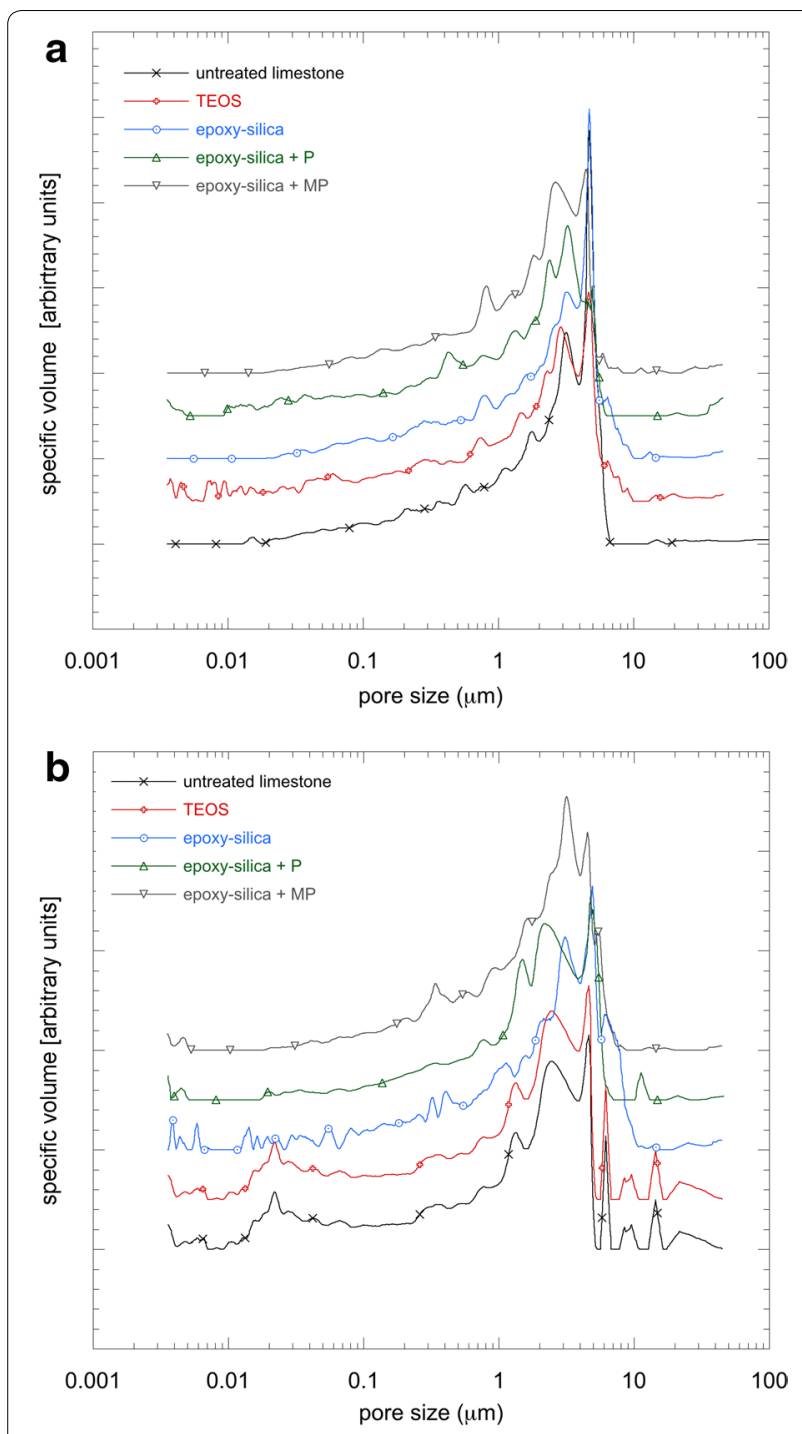

Fig. 4 Pore size distribution for untreated and immersion consolidated GL blocks $\mathbf{a}$ as-applied, before weathering, $\mathbf{b}$ after weathering

\section{Drilling resistance}

The drilling resistance of brush-applied consolidants are presented in Fig. 7a while drilling resistance of the treated GL blocks after weathering are given in Fig. 7b. Untreated and non-weathered GL showed least resistance to drilling; the resistance force curve increased steeply as the drill bit bored through the first few millimetres of limestone reaching a plateau with an average drilling resistance of $10 \mathrm{~N}$. The curve for TEOS treated limestone presented a similar shape reaching a plateau at $\sim 12 \mathrm{~N}$, an improvement over untreated limestone. The drilling forces increased steeply reaching maxima at approximately $1 \mathrm{~mm}$ depth, following which curves dropped steadily approaching the value of untreated limestone. Resistance maxima were $14 \mathrm{~N}, 17 \mathrm{~N}$ and $20 \mathrm{~N}$ for epoxy-silica, nanoparticle-loaded hybrid and modified nanoparticle-loaded hybrid respectively. Drilling resistance maxima are indicative of consolidant accumulation beneath the stone surface.

The drilling resistance curves for brush-consolidated stone after weathering are given in Fig. 7b. Weathering has no effect on the TEOS-consolidated limestone curve with the drilling force remaining stable at $\sim 12 \mathrm{~N}$. The drilling resistance of the untreated limestone actually improved with weathering. The wet-dry cycles drive the dissolution-precipitation of calcite with the latter depositing at weak spots, and serving as the consolidant material. Weathering negatively impacts the mechanical properties of the epoxy-silica consolidants and almost all benefits from consolidation are lost after weathering: the resistance curve maxima were significantly reduced, and the drilling resistance curves approached the profile of untreated limestone.

The drilling resistance curves for stone blocks treated by full immersion are presented in Fig. 7c. The curve for TEOS consolidated stone was identical to that achieved by brush-application. The mechanical properties of epoxy-silica consolidants applied by immersion were improved however: the drilling resistance maxima occur deeper in the stone $\sim 1-3 \mathrm{~mm}$ and resistance force maxima were also larger $\sim 60 \mathrm{~N}$ for the epoxy-silica, $\sim 75 \mathrm{~N}$ for nanoparticle-loaded hybrid, and $\sim 22 \mathrm{~N}$ for modified nanoparticle-loaded hybrid. The profile for TEOS treated GL remained unaltered after weathering, Fig. 7d. Weathering led to a reduction in the drilling force maximum of epoxy-silica consolidant $\sim 32 \mathrm{~N}$ at $2 \mathrm{~mm}$ depth. The drilling resistance profiles for nanoparticle- and modified nanoparticle-loaded hybrids were also affected; the drilling resistance curves plateau at respectively $20 \mathrm{~N}$ and $22 \mathrm{~N}$ and then further dropped with increased drilling depth.

\section{Salt crystallisation test}

The results of the sodium sulphate salt crystallisation test on GL blocks consolidated by brushing are presented in Fig. 8a while the corresponding results after weathering are given in Fig. 8b. Treated and untreated stone blocks lose material with successive salt crystallization cycles after cycle 3, but whereas untreated and TEOSconsolidated stone blocks survived relatively intact up to cycle 12 , losing less than $5 \%$ of their respective masses, epoxy-silica consolidated limestone blocks lost significant mass $(>8 \%)$ by cycle 6 . The situation did not change after weathering: by cycle 6 , stone blocks treated to the epoxy-silica consolidants lost considerably more 
Table $2 \%$ open porosity, absorption coefficient and water absorption before and after weathering for consolidated and untreated GL blocks. Consolidant was applied by brush and immersion

\begin{tabular}{|c|c|c|c|c|c|c|}
\hline Consolidant system & $\begin{array}{l}\% \text { Open } \\
\text { porosity } \\
\text { (v/v) } \\
\text { Before } \\
\text { weathering }\end{array}$ & $\begin{array}{l}\text { \% Open } \\
\text { porosity } \\
(\mathrm{v} / \mathrm{v}) \\
\text { After } \\
\text { weathering }\end{array}$ & $\begin{array}{l}\text { Absorption } \\
\text { coefficient (g/ } \\
\mathrm{m}^{2} \mathrm{~s}^{0.5} \text { ) } \\
\text { Before } \\
\text { weathering }\end{array}$ & $\begin{array}{l}\text { Absorption } \\
\text { coefficient (g/ } \\
\mathrm{m}^{2} \mathrm{~s}^{0.5} \text { ) } \\
\text { After } \\
\text { weathering }\end{array}$ & $\begin{array}{l}\text { Water absorption } \\
\text { (\%, w/w, @ } 24 \text { h) } \\
\text { Before } \\
\text { weathering }\end{array}$ & $\begin{array}{l}\text { Water absorption } \\
\text { (\%,w/w, @ } 24 \text { h) } \\
\text { After weathering }\end{array}$ \\
\hline \multicolumn{7}{|l|}{ Consolidant applied by brush } \\
\hline Untreated limestone & 39.9 & 39.6 & $10.26 \pm 0.63$ & $7.72 \pm 0.44$ & $13.52 \pm 0.47$ & $13.92 \pm 0.13$ \\
\hline TEOS & - & - & $3.54 \pm 1.25$ & $2.73 \pm 0.38$ & $12.53 \pm 0.50$ & $13.34 \pm 0.18$ \\
\hline Epoxy-silica & - & - & $6.84 \pm 1.01$ & $6.64 \pm 0.88$ & $13.21 \pm 0.50$ & $13.63 \pm 1.40$ \\
\hline Epoxy-silica + nanoparticles & - & - & $8.57 \pm 1.56$ & $8.41 \pm 1.51$ & $13.39 \pm 0.03$ & $13.70 \pm 0.22$ \\
\hline Epoxy-silica + modified nanoparticles & - & - & $7.71 \pm 0.41$ & $7.91 \pm 1.45$ & $13.36 \pm 0.43$ & $13.80 \pm 0.12$ \\
\hline \multicolumn{7}{|l|}{ Consolidant applied by immersion } \\
\hline Untreated limestone & 39.9 & 39.6 & $10.26 \pm 0.63$ & $7.72 \pm 0.44$ & $13.52 \pm 0.47$ & $13.92 \pm 0.13$ \\
\hline TEOS & 35.5 & 39.9 & $0.52 \pm 0.37$ & $0.20 \pm 0.04$ & $3.88 \pm 2.67$ & $1.70 \pm 0.30$ \\
\hline Epoxy-silica & 35.6 & 39.5 & $0.14 \pm 0.05$ & $2.37 \pm 0.54$ & $2.78 \pm 1.61$ & $12.40 \pm 0.41$ \\
\hline Epoxy-silica + nanoparticles & 33.9 & 39.5 & $0.49 \pm 0.20$ & $3.49 \pm 0.71$ & $5.57 \pm 6.77$ & $12.47 \pm 0.12$ \\
\hline Epoxy-silica + modified nanoparticles & 34.2 & 35.8 & $6.10 \pm 0.89$ & $7.87 \pm 2.00$ & $12.33 \pm 0.16$ & $12.57 \pm 0.05$ \\
\hline
\end{tabular}

material compared to TEOS/untreated limestone, but not as much as for the un-weathered consolidated stone.

The salt crystallisation test results for consolidants applied by immersion, and the same consolidants after weathering are presented in Fig. 8c, d. Limestone blocks treated to TEOS and hybrid + modified NP survived 12 crystallization cycles. Stone blocks treated to epoxysilica and nanoparticle-loaded hybrid survived nine crystallisation cycles following which they failed catastrophically by breaking into large pieces. The weathering protocol negatively affected the group of epoxy-silica consolidated stone; GL blocks failed catastrophically by cycle 8 , losing over $10 \%$ of their mass. Although minor, weathering led to poorer behaviour of untreated and TEOS-treated GL blocks in the salt crystallisation test.

\section{Discussion}

\section{Influence of weathering on water transport properties}

Electron micrographs of immersion-applied epoxy-silica consolidants, show them lining the surfaces of pores rather than blocking them. The pore size distributions indicate that the applied consolidants have not entirely clogged stone pores, though undoubtedly some blockage has occurred as observed by the 4-6\% (v/v) drop in total open porosity for stone treated by immersion. Pore blocking was marginally higher for the particleloaded hybrids $\sim 2 \%$. This blocking has disturbed the water flow characteristics of the stone so that the average water absorption coefficients of epoxy-silica consolidated limestone blocks (immersion method) were low, or very low and comparable to TEOS. With the exception of the modified nanoparticle-loaded hybrid, weathering restored the total open porosity for all consolidated GL blocks, and this also brought about an improvement in the absorption coefficients.

Influence of artificial weathering on consolidation strength The drilling resistance of epoxy-silica consolidants showed that penetration by a double-brush application reached depths of $\sim 8 \mathrm{~mm}$ and correspondingly larger drilling resistance forces of about 5-10 $\mathrm{N}$ above the value of untreated GL. The immersion treatment presented even higher drilling resistance maxima, $\sim 10 \mathrm{~N}$, and up to $60 \mathrm{~N}$ above untreated GL, and penetration depths in excess of $10 \mathrm{~mm}$. The highest drilling resistance values were measured for nanoparticle-loaded consolidants. Weathering however resulted in a drop in the drilling resistance for the epoxy-silica consolidant group and this irrespective of the application method employed. These results show that epoxy-silica consolidants have lost their mechanical strength with prolonged contact with water. This loss in strength is tentatively explained as follows: The $\mathrm{pH}$ of water film in contact with limestone depends on the partial pressure of atmospheric $\mathrm{CO}_{2}$ and in open atmosphere is typically around 8.3 [22]. When atmospheric $\mathrm{CO}_{2}$ is reduced, as could happen deep inside the consolidated pore network, the $\mathrm{pH}$ can approach values as high as 9.9 [25]. In a recent study, the $\mathrm{pH}$ of an aqueous suspension of calcite powder was found to be between 9.5 and 9.7 [26]. Under such alkaline conditions, exposed siloxane bonds ( $\equiv \mathrm{Si}-\mathrm{O}-\mathrm{Si} \equiv$ ) are susceptible to hydrolysis forming silanol groups $(\equiv \mathrm{Si}-\mathrm{OH})$ [22]. The larger the fraction of severed siloxane links, the weaker the 

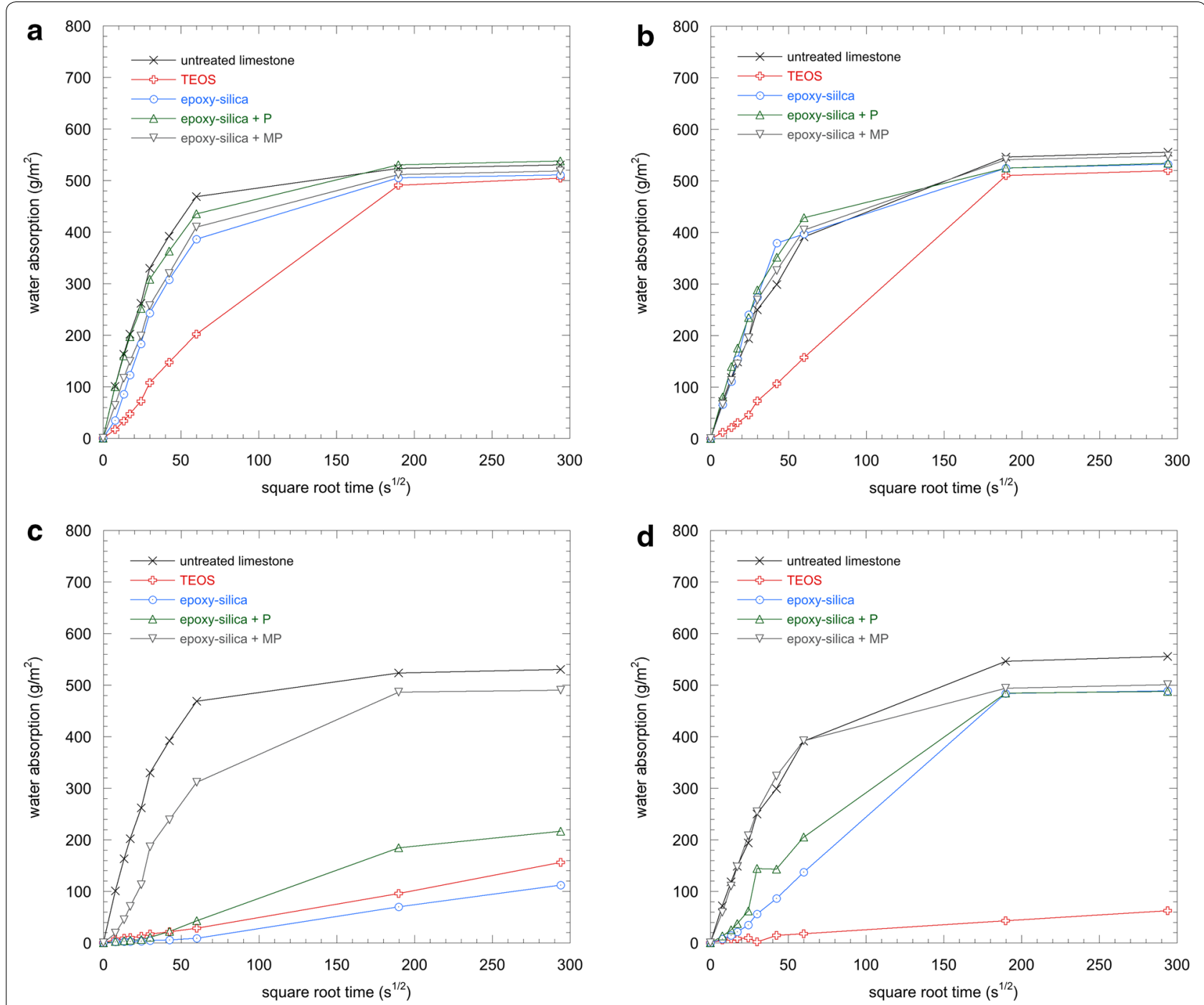

Fig. 5 Water uptake by capillarity curves for a brush-consolidated GL before weathering, $\mathbf{b}$ after weathering, $\mathbf{c}$ immersion-consolidated before weathering, $\mathbf{d}$ after weathering

inorganic network. The newly formed silanol groups will also absorb and retain water by hydrogen bonding, transforming the consolidant into a gel with inferior mechanical properties.

No loss of drilling resistance was measured for TEOS-consolidated GL, but here the consolidant is hydrophobic and remains so for some time. Indeed TEOS consolidant films can potentially experience a similar fate on prolonged contact with water and once the hydrophobic properties are lost. De Ferri and coauthors [8] reported an unexplained drop in the water contact angle of one of their more hydrophobic epoxysilica consolidants applied to marble and sandstone in continuous contact with water for a few days. Under such test conditions, siloxane bonds could have been hydrolysed with the formation of silanol groups that in turn lower the water contact angle.

\section{Influence of consolidant strength on the salt crystallisation test}

The results of the salt crystallisation tests are not forthcoming. Epoxy-silica consolidated GL blocks were outperformed by untreated and TEOS-treated limestone. This failure was attributed to over-strengthening of stone blocks at zones beneath the surface where consolidant material accumulated, corresponding to the observed drilling resistance force maxima. In the salt crystallisation test, salt is repeatedly crystallized inside the stone pore network promoting surface expansive stresses. After a number of cycles, the stone surface layer eventually 

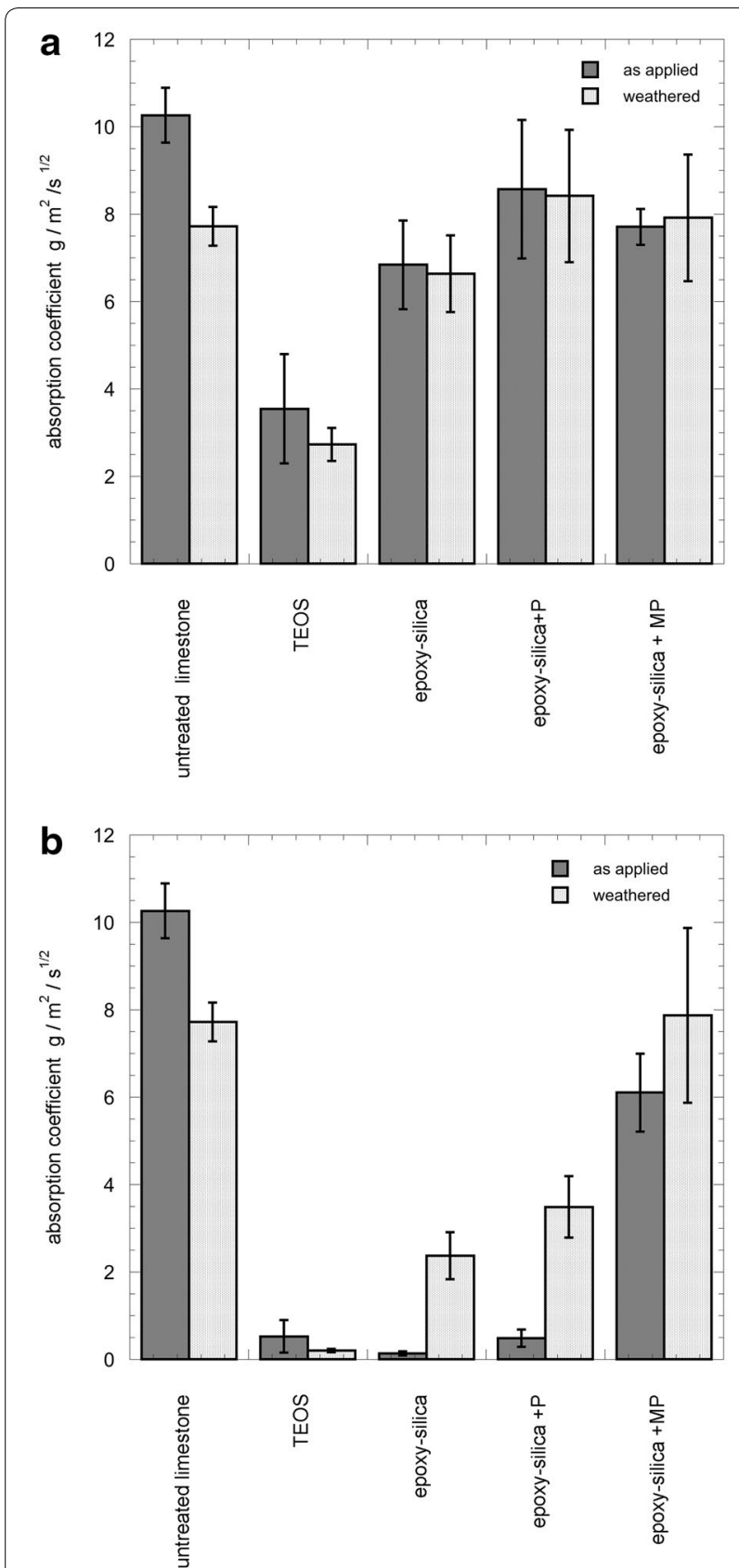

Fig. 6 Water absorption coefficients before and after weathering for consolidants applied by $\mathbf{a}$ brush, $\mathbf{b}$ immersion

succumbs to the stresses resulting in surface flaking. Failure occurs at sites where stone is mechanically weakest. Delgado observed that for an non-homogeneously deposited consolidant, failure generally occurred at the interface demarking the outer very hard and overstrengthened consolidated layer, and the inner less consolidated and consequently less resistant zone [27]. Consequently, the harder and thicker the strengthened layer, the more pronounced the mass loss when that layer eventually succumbs. This is because material is lost as thick consolidated layers rather than thin flakes. Indeed, this was observed for the epoxy-silica consolidated GL blocks prepared in this work; the onset of failure for un-weathered consolidated stone was typically marked by a sharp drop in mass followed by a recovery period as salt re-accumulated in the freshly exposed stone. As expected, mass loss was more pronounced in stone blocks treated by immersion where penetration was deeper.

It is interesting to see how weathering alters the salt crystallisation results. For the brush-applied epoxy-silica consolidants, the average \% mass loss rate decreased after weathering. For example, at cycle 6 the average \% mass loss for limestone blocks treated to epoxy-silica consolidants was $7-14 \%(\mathrm{w} / \mathrm{w})$; after weathering this average decreased to $4-7 \%(\mathrm{w} / \mathrm{w})$. This result agrees with the drilling resistance data and reinforces the idea that the consolidants are weakened with repeated weathering cycles.

Unexpectedly, for epoxy-silica consolidants applied by immersion, weathering led to a drop in the crystallisation resistance. For example, by cycle 8 , limestone lost $<5 \%(\mathrm{w} / \mathrm{w})$, compared to $>10 \%(\mathrm{w} / \mathrm{w})$ after weathering. This behaviour was due to pore blocking $\sim 4-6 \%$, Table 2. With pores blocked by consolidant, penetration of salt solution was reduced and the stone 'appeared' to behave better in the salt crystallisation test (TEOS works in a similar manner to preventing salt solution from penetrating the stone). Artificial weathering unblocks these pores resulting in an apparent overall poorer performance.

A comparison between the performances of the different epoxy-silica consolidants in the salt crystallisation test showed that modified particle-loaded hybrid gave the best overall result, irrespective of the application technique. Better bonding of the surface modified particles with the matrix is thought to be a contributing factor.

\section{Conclusion}

In this work an epoxy-silica consolidant, and variants loaded with silica NP were applied to GL. The consolidants penetrated to depths of $8-10 \mathrm{~mm}$, and were observed to line the stone pores with minimal changes to the pore size distribution. A $4-6 \%(\mathrm{v} / \mathrm{v})$ drop in open porosity was nonetheless recorded for epoxy-silica consolidants applied by immersion treatment, suggesting 

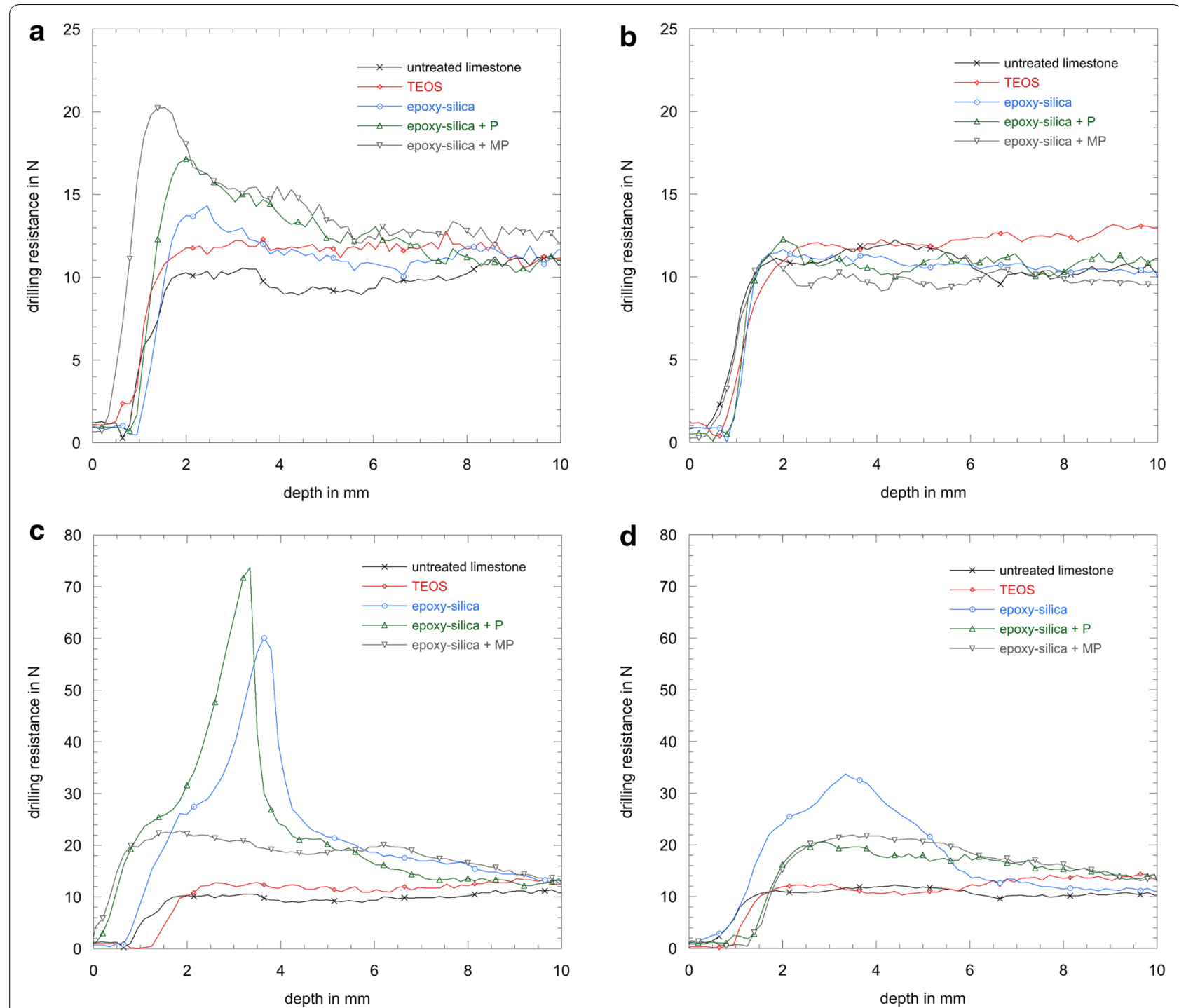

Fig. 7 Representative drilling resistance force curves for untreated and consolidated GL blocks a brush-consolidated, $\mathbf{b}$ brush-consolidated and weathered, $\mathbf{c}$ immersion-treated, $\mathbf{d}$ immersion-treated and weathered

that some pores, presumably the smaller diameter ones, were blocked by the consolidants. The effect was minimal for consolidants applied by brush but severe for immersion application. The epoxy-silica consolidants also led to significant stone colour alteration and a drop in the water absorption coefficients.

Consolidation improved the mechanical properties of the untreated limestone. Improvements were most pronounced for the epoxy-silica consolidants as attested by the drilling force profiles. The improved mechanical properties imparted by these consolidants however deteriorated significantly after the weathering protocol and prolonged contact with water. The drop in mechanical properties is thought to occur by hydrolysis of the inorganic silica network, catalysed by the alkaline surroundings. The results of the salt crystallisation test expose another serious problem with the epoxy-silica consolidants, namely that, the latter accumulate at the surface 

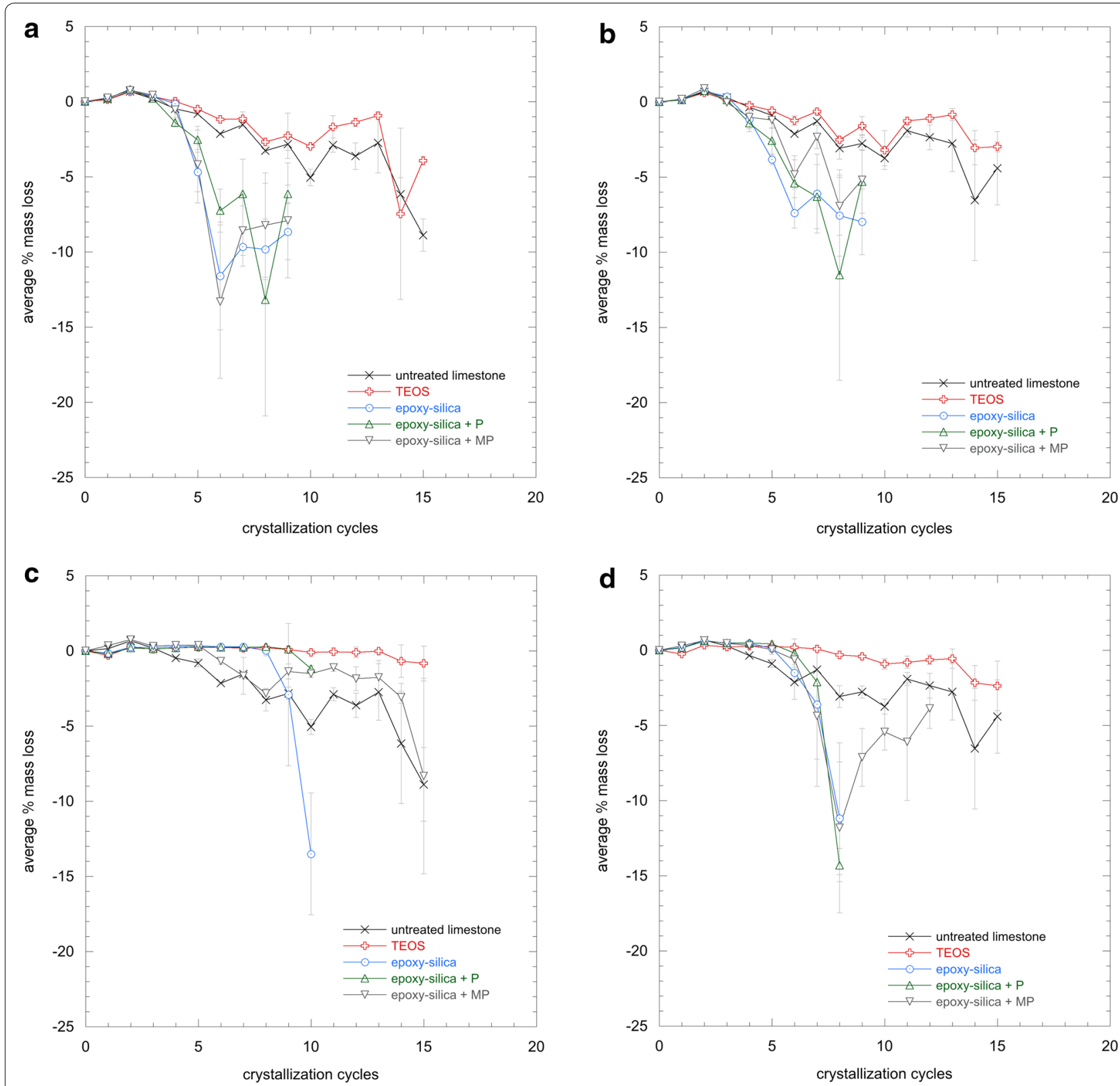

Fig. 8 Average \% mass loss with crystallisation cycles for $\mathbf{a}$ brush-consolidated, $\mathbf{b}$ brush-consolidated and weathered, $\mathbf{c}$ immersion-treated, $\mathbf{d}$ immersion-treated and weathered

forming an effective crust. This seems to be independent of the application technique. The consequence of this being that significantly more stone material is lost in the salt crystallisation test.

This work has shown that water-based epoxy-silica consolidants with and without nanoparticles are currently not effective consolidants for Globigerina Limestone. Even if aesthetical issues can be overcome (for example by limiting the amount of consolidant applied to the stone or changing solvent), issues of long-term environmental stability remain pertinent. This work nonetheless emphasizes the need for a more holistic evaluation of stone consolidants which should include a weathering protocol.

\section{Abbreviations}

NP: nanoparticles; GL: Globigerina Limestone; TEOS: tetraethylorthosilicate; GPTMS: 3-glycidoxypropyl trimethoxysilane; PDMS-OH: poly(dimethylsiloxane); DBTL: dibutyltin dilaureate; DETA: diethylenetriamine. 


\section{Authors' information}

Dr. Sophie M. Briffa is currently a research fellow at the University of Birmingham, UK.

Dr. Daniel A. Vella holds a lecturing position at the University of Malta. Prior to joining the University, Daniel Vella has worked as a Conservation Scientist with Heritage Malta for 9 years.

\section{Acknowledgements}

The authors are in debt to Prof. M. J. Mosquera for allowed access to the mercury intrusion porosimeter at the University of Cadiz, Spain.

\section{Authors' contributions}

SMB carried out the experimental work and prepared a first draft of the paper. DAV supervised the experimental work, contributed to the interpretation of the results and prepared the final manuscript. Both authors read and approved the final manuscript.

\section{Funding}

This work was funded through the EU funded project Towards Strategic Educational Pathways Scheme (Malta) (Grant no. 6573) and ERDF (Malta) "Developing an Interdisciplinary Material Testing and Rapid Prototyping R\&D Facility (Ref. no. 012)".

\section{Availability of data and materials}

All data generated or analysed during this study are included in this published article.

\section{Competing interests}

The authors declare that they have no competing interests.

Received: 20 December 2018 Accepted: 29 April 2019

Published online: 13 May 2019

\section{References}

1. Doehne E, Price CA. Stone conservation, an overview of current research. 2nd ed. Los Angeles: The Getty Conservation Institute; 2010.

2. Delgado Rodrigues J. Stone consolidation: research and practice. In: Int. symp. On works of art and conservation science today, Thessaloniki, Greece. 2010;1:1-8.

3. ASTM. Standard guide for selection and use of stone consolidants. 2008; E 2167-01.

4. Wheeler G. Alkoxysilanes and the consolidation of stone. Los Angeles: The Getty Conservation Institute; 2005. p. 31-54.

5. Xu F, Xiang N, Li D, Yu J, Wu D, Zhang Q. Use of coupling agents for increasing passivants and cohesion ability of consolidant on limestone. Prog Org Coat. 2014;77(11):1613-8.

6. Cardiano P, Ponterio RC, Sergi S, Schiavo SL, Piraino P. Epoxy-silica polymers as stone conservation materials. Polymer. 2005;46:1857-64.

7. Kim EK, Won J, Do J, Kim SD, Kang YS. Effects of silica nanoparticle and GPTMS addition on TEOS-based stone consolidants. J Cult Heritage. 2009;10(2):214-21.

8. De Ferri L, Lottici PP, Lorenzi A, Montenero A, Salvioli-Mariani E. Study of silica nanoparticles - polysiloxane hydrophobic treatments for stonebased monument protection. J Cult Heritage. 2011:12(4):356-63.

9. Xu F, Wang C, Li D, Wang M, Xu F, Deng X. Preparation of modified epoxy$\mathrm{SiO}_{2}$ hybrid materials and their application in the stone protection. Prog Org Coat. 2015;81:58-65.

10. Cassar J. Deterioration of the Globigerina Limestone of the Maltese islands. In: Siegesmund S, Weiss T, Vollbrecht A, editors. Natural stone, weathering phenomena, conservation strategies and case studies. London: The Geological Society of London; 2002. p. 33-49.

11. Rothert E, Eggers T, Cassar J, Ruedrich J, Fitzner B, Siegesmund S. Stone properties and weathering induced by salt crystallization of maltese Globigerina Limestone. In: Prikryl R, Smith BJ, editors. Building stone decay: from diagnosis to conservation. London: Geological Society; 2007. p. 189-98.

12. Smith BJ, Gomez-Heras M, Viles HA, Cassar J, editors. Limestone in the built environment, present day challenges for the preservation of the past. London: The Geological Society; 2010.

13. Briffa SM, Sinagra E, Vella DA. TEOS based consolidants for Maltese Globigerina Limestone: effect of hydroxyl conversion treatment. In: Proceedings of the 12th international congress on the deterioration and conservation of stone, New York City. 2012. p. 1-11.

14. Vreugdenhil A, Balbyshev V, Donley M. Nanostructured silicon solgel surface treatments for al 2024-T3 protection. J Coat Technol. 2001;73(915):35-43.

15. Balbyshev VN, Anderson KL, Sinsawat A, Farmer BL, Donley MS. Modeling of nano-sized macromolecules in silane-based self-assembled nanophase particle coatings. Prog Org Coat. 2003:47(3):337-41.

16. Palazzi S. Colorimetria: La scienza del colore nell'arte e nella tecnica. Firenze: Nardini Editore; 1995.

17. Ferreira Pinto AP, Delgado Rodrigues J. Stone consolidation: the role of treatment procedures. J Cult Heritage. 2008;9:38-53.

18. Cornell RM, Schwertmann U. The iron oxides, structure, properties, reactions, occurrences and uses. 2nd ed. Weinheim: Wiley-VCH GmbH; 2000

19. Baer NS, Snethlage R. Methods for the evaluation of stone conservation treatments. In: Saving our architectural heritage: the conservation of historic stone structures. Report of the Dahlem Workshop on Saving our Architectural Heritage: the Conservation of Historic Stone Structures. Wiley, 3-8th March 1996, Berlin, Germany.

20. Miliani C, Velo-Simpson ML, Scherer GW. Particle-modified consolidants: a study on the effect of particles on sol-gel properties and consolidation effectiveness. J Cult Heritage. 2007;8:1-6.

21. Maravelaki-Kalaitzaki P, Kallithrakas-Kontos N, Agioutantis Z, Maurigiannakis S, Korakaki D. A comparative study of porous limestones treated with silicon-based strengthening agents. Prog Org Coat. 2008;62(1):49-60.

22. Brinker CJ, Scherer GW. Sol-gel science: the physics and chemistry of solgel processing. San Diego: Academic Press Inc.; 1990. p. 908.

23. Scherer GW, Wheeler G. Silicate consolidants for stone. Key Eng Mater 2009;391:1-25

24. Said Conti M. Characterization and testing of nano-structured hybrid solgel coatings for the corrosion protection of low carbon steel. [B.Sc. long project]. University of Malta; 2012

25. Livingstone R. Geochemical considerations in the cleaning of carbonate stone. In: Webster R, editor. Stone cleaning and the nature, soiling and decay mechanisms of stone. 1992. p. 166-79.

26. Fonseca SD, Ferreira MJ, Taryba MG, PiçArra S, Ferreira Pinto AP, Montemor MdF. Alkoxysilane-based sols for consolidation of carbonate stones: impact of the carbonate medium in the sol-gel processes. J Cult Heritage. 2018. https://doi.org/10.1016/j.culher.2018.11.007.

27. Delgado Rodrigues J. Consolidation of decayed stones. A delicate problem with few practical solutions. In: Lourenco PB, Roca Guimaraes P, editors. Historical constructions. 2001. p. 3-14.

\section{Publisher's Note}

Springer Nature remains neutral with regard to jurisdictional claims in published maps and institutional affiliations. 